\title{
Ventriculoperitoneal shunt failure from spontaneous knotting of the peritoneal catheter
}

\author{
Patrick J. McDonald MD MHSc
}

$\mathrm{A}$ 15-month-old girl with hydrocephalus from an intraventricular hemorrhage presented to the emergency department with irritability, lethargy and vomiting. Our neurosurgery team had inserted a ventriculoperitoneal shunt 10 months earlier. Computed tomography of the patient's brain showed enlarged ventricles relative to postoperative imaging from when she had been asymptomatic. The child was brought to the operating room for exploration and revision of her shunt.

At the time of surgery, the ventricular portion of the catheter was disconnected from the valve. Good flow of cerebrospinal fluid was seen, suggesting a properly functioning ventricular catheter. The peritoneal portion of the shunt was disconnected from the valve and tested, showing no flow through the peritoneal end of the catheter. For this reason, the entire shunt was replaced. When the peritoneal end of the shunt was removed from the abdomen, it was found to be doubly knotted (Figure 1), which was the likely cause of the shunt's failure. Because there was no evidence of knotting at the time of first insertion, we hypothesize that the normal peristaltic movements of the bowel caused the catheter to knot. We do not routinely perform imaging for shunts after insertion, so we could not determine exactly when the shunt knotted. ${ }^{1}$ It is possible that the shunt was inadvertently loosely knotted at the time of insertion. Following shunt replacement, the child returned to her baseline level of functioning.

Shunt failure is unfortunately quite common; most infants with a shunt require revision of the shunt at some point in the first three years after insertion. ${ }^{2}$ Despite the high failure rate, shunting remains the mainstay of treatment for symptomatic hydrocephalus in children and adults. Most patients with shunt failure present with signs of raised intracranial pressure, such as irritability, headache, nausea, vomiting and lethargy. ${ }^{3}$ Shunt failures usually occur at the ventricular end of the shunt, ${ }^{4}$ with blockage of the ventricular cath-

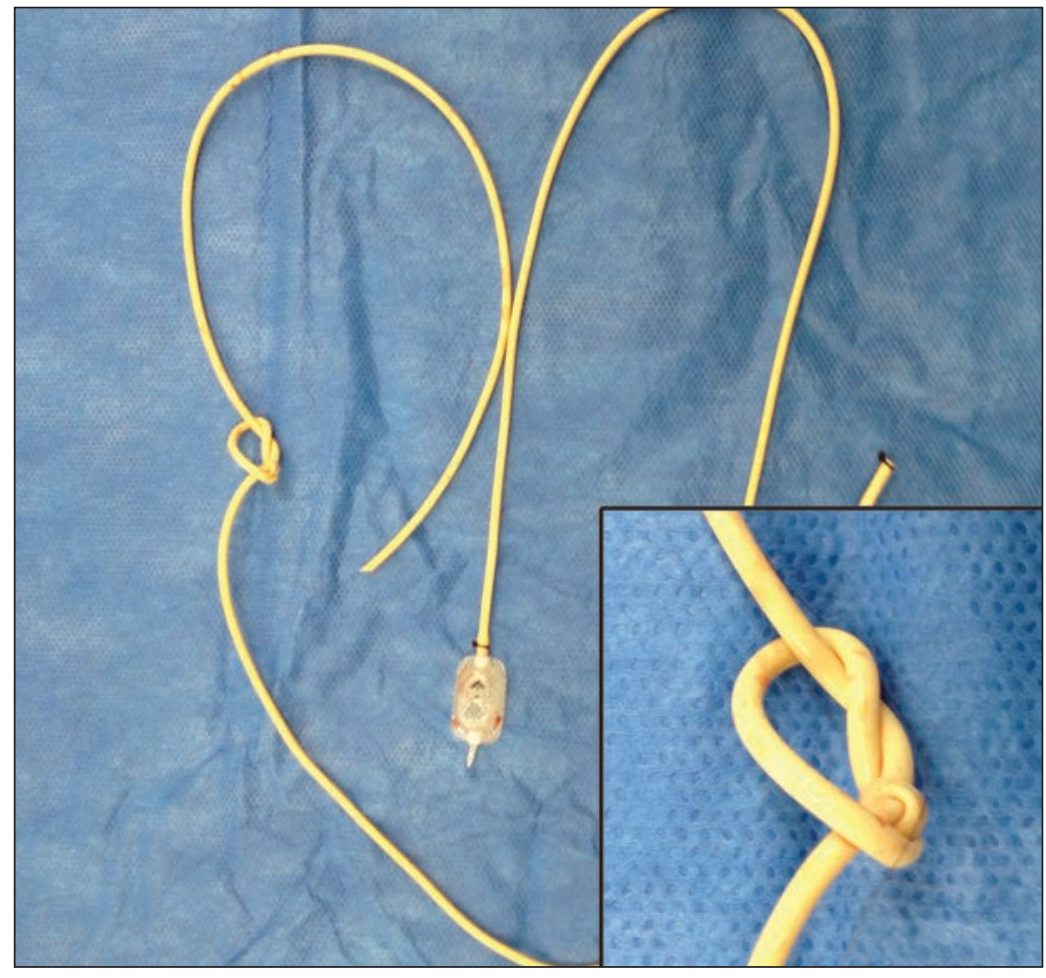

Figure 1: Complete ventriculoperitoneal shunt showing a double-knotted peritoneal catheter after removal from a 15-month-old girl who presented with signs and symptoms of shunt failure. Inset: Close up of the double knot.

eter by debris. Knotting of the peritoneal catheter with subsequent shunt failure remains an uncommon complication of shunting. ${ }^{5}$

\section{References}

1. Vassilyadi M, Tataryn ZL, Alkherayf F, et al. The necessity of shunt series. J Neurosurg Pediatr 2010;6:468-73.

2. Drake JM, Kestle JR, Milner R, et al. Randomized trial of cerebrospinal fluid shunt valve design in pediatric hydrocephalus. Neurosurgery 1998;43:294-303.

3. Khan AA, Jabbar A, Banerjee A, et al. Cerebrospinal shunt malfunction: recognition and emergency management. Br J Hosp Med (Lond) 2007;68:651-5.

4. Blegvad C, Skjolding AD, Broholm H, et al. Pathophysiology of shunt dysfunction in shunt treated hydrocephalus. Acta Neurochir (Wien) 2013;155:1763-72.

5. Tan LA, Kasliwal MK, Moftakhar R, et al. Ventriculoperitoneal shunt with a rare twist: small-bowel ischemia and necrosis secondary to knotting of peritoneal catheter. J Neurosurg Pediatr 2014; $14: 234-7$.
Competing interests: None declared.

This article has been peer reviewed.

The author has obtained patient consent.

Affiliation: Section of

Neurosurgery and Department of Pediatrics and Child Health, College of Medicine, University of Manitoba, Winnipeg, Man.

Correspondence to:

Patrick McDonald, pmcdonald@hsc.mb.ca

CMAJ 2016. DOI:10.1503 /cmaj.150635 